www.jmscr.igmpublication.org

Index Copernicus Value: 79.54

ISSN (e)-2347-176x ISSN (p) 2455-0450

crossrefDOI: https://dx.doi.org/10.18535/jmscr/v7i3.175

Journal Of Medical Science And Clinical Research

IGM Publication

An Official Publication of IGM Publication

\title{
A Comparative Efficacy of two Regional Techniques for Labour Analgesia: Combined Spinal Epidural Analgesia versus Epidural Analgesia
}

\author{
Authors
}

\author{
Dr D.Kailashini ${ }^{1}$, Dr P.Sudha Poornima ${ }^{2}$, Dr A. Satyanarayana ${ }^{3}$
}

Department of Anesthesiology, Andhra Medical College, Visakhapatnam, India

\begin{abstract}
Background and Aim: Central Neuraxial analgesia is the most versatile method of labour analgesia and the gold standard technique for pain control in obstetrics that is currently available. The satisfaction of birth experience is greater with neuraxial techniques. Neuraxial analgesia is the mainstay analgesic, frequently administered to women in labor.we aimed at comparing efficacy of two regional techniques for labour analgesia by combined spinal epidural analgesia versus epidural analgesia evaluating by onset of analgesia, duration of analgesia, maternal satisfication, mode of delivery, neonatal outcome, complications(maternal and fetal).

Materials and Methods: 40 parturient of ASA physical status I or II in active labor with a cervical dilatation of 3$6 \mathrm{~cm}$ requesting labour analgesia were motivated and enrolled were divided into two groups.

Group A:Received combined spinal Epidural technique using Intrathecal dose $1 \mathrm{ml}$ of solution containing $1 \mathrm{mg}$ of $0.5 \%$ Hyperbaric Bupivacaine $+25 \mathrm{mcg}$ Fentanyl.Followed by subsequent top ups on patient demand using $10 \mathrm{ml}$ of solution containing 0.1\% Bupivacaine $+2 \mathrm{ug} / \mathrm{ml}$ of Fentanyl. Group B: Received Epidural analgesia bolus dose of $10 \mathrm{ml}$ solution $0.1 \%$ Bupivacaine $+2 \mathrm{mcg} / \mathrm{ml}$ of Fentanyl. Intermittent top ups on patient demand using $10 \mathrm{ml}$ solution containing $0.1 \%$ Bupivacaine $+2 \mathrm{mcg} / \mathrm{ml}$ of Fentanyl. Onset of analgesia, Mode of delivery, Neonatal outcome,Maternal satisfaction, Complications (maternal and fetal) were assessed. pain intensity by using a numerical rating scale and motor block by using bromage scale.

Results: Eighteen parturients from CSEA had onset of analgesia in less than $5 \mathrm{~min}$, twelve parturient from LEA group had Onset of analgesia between 11 to $15 \mathrm{~min}$ and seven parturients had onset of analgesia between 1620 min. The mean time of onset of analgesia in Group A was $5.05 \pm 2.25$ Min. The mean time of onset of analgesia in Group B was $15.2 \pm 1.93$ Min. Eighteen parturients from Group had undergone normal vaginal delivery. One parturient from Group B had underwent caesarian section for different indication. One parturient from Group $B$ had undergone delivery in instrumental mode. All the Neonates from Group A and Group B had Apgar score of at 5 th min of delivery. There was no difference in neonatal outcome between two groups. Five parturients in Group A complained of Pruritis and none of the parturients in group B complained of pruritis. Two parturients from each group had Hypotension. None of the parturients in neither group had other Complications like nausea and vomiting, non progressive labor or fetal distress.

Conclusion: From the present study we conclude that both the techniques Combined spinal Epidural and Epidural for labor analgesia produce excellent analgesia. However the CSE technique had faster onset of analgesia when compared to Epidural technique. Both the technique were similar in terms of safety and efficacy.

Keywords: Labour analgesia, Combined spinal epidural analgesia, epidural analgesia.
\end{abstract}

\section{Introduction}

"The delivery of the infant into the arms of a conscious and pain free mother is one of the most exciting and rewarding moments in medicine.

\section{MOIR DD}

Labour is a physiologic process but associated with severest form of pain. 
Unrelieved stress in labour produces increased plasma cortisol and catecholamines concentrations which reduces utero-placental blood flows by $35-$ $70 \%$ compounding the effects of hyperventilation on the oxygen supply to the foetus. ${ }^{1}$

Metabolic acidosis as a result of increase metabolic rates especially in the second stage of labour is transferred to the foetus. there is delayed gastric emptying and urinary emptying. ${ }^{2}$

Effective pain relief reduces plasma noradrenaline ${ }^{3}$, prevents the rise during first and second stage of labour of 11-hydroxy corticosteroid $^{4}$, prevents metabolic acidosis by reducing the rate of rise of lactate and pyruvate. $^{5}$ The pain-induced hyperventilation and hypocapnia ${ }^{6}$ reduces utero-placental blood flow by $25 \%$.

The respiratory alkalosis further impairs foetomaternal gas exchange by shifting the oxyhaemoglobin dissociation curve to the left and fetal $\mathrm{PaO} 2$ may fall by $23 \%$.

There have been no proven scientific data analysis of the quality of pain relief offered by non pharmacological methods ${ }^{11}$ neither transcutaneous electric nerve stimulation nor inhalation of entonox was not adequate for pain relief in labour. Central neuraxial analgesia is the most versatile method of labour analgesia and the gold standard technique for pain control in obstetrics that is currently available. ${ }^{7}$ Epidural analgesia was associated with greater pain relief than non epidural methods however it is associated with longer first and second stage of labour. An increased incidence of fetal malposition and increased use of oxytocin and instrumental vaginal deliveries. Combined spinal epidural analgesia is as safe as conventional epidural technique and is associated with greater maternal satisfaction $^{12}$

The satisfaction of birth experience is greater with neuraxial techniques.. ${ }^{7}$ Neuraxial analgesia is the mainstay analgesic, frequently administered to women in labor. $8,9,10$

On this background we tried to compare both the techniques combined spinal epidural and epidural in labour analgesia in order to evaluate onset, efficacy of analgesia and safety of mother and fetus.

\section{Aims and Objectives}

The aim of the study is to compare efficacy of two regional techniques for labour analgesia using combined spinal epidural analgesia versus epidural analgesia

The parameters studied are

1. Onset of analgesia.

2. Mode of delivery.

3. Neonatal outcome.

4. Maternal satisfaction.

5. Complications (maternal and fetal).

\section{Materials and Methods}

Study was conducted in the Department of Anesthesiology in association with Department of Gynecology and Obstetrics at King George Hospital, Visakhapatnam .40 parturient of ASA physical status I or II in active labor with a cervical dilatation of $3-6 \mathrm{~cm}$ requesting epidural analgesia were motivated and enrolled.

They were divided into two groups.

Group A: Received combined spinal Epidural technique using Intrathecal dose $1 \mathrm{ml}$ of solution containing $1 \mathrm{mg}$ of $0.5 \%$ Hyperbaric Bupivacaine $+25 \mathrm{mcg}$ Fentanyl .Followed by subsequent top ups on patient demand using $10 \mathrm{ml}$ of solution containing $0.1 \%$ Bupivacaine $+2 \mathrm{ug} / \mathrm{ml}$ of Fentanyl

Group B: Received Epidural analgesia bolus dose of $10 \mathrm{ml}$ solution $0.1 \%$ Bupivacaine $+2 \mathrm{mcg} / \mathrm{ml}$ of Fentanyl.Intermittent top ups on patient demand using $10 \mathrm{ml}$ solution containing $0.1 \%$ Bupivacaine $+2 \mathrm{mcg} / \mathrm{ml}$ of Fentanyl.

\section{Inclusion Criteria}

a) Healthy Primigravida and gravida 2 patients at term.

b) ASA (American Society of Anesthesiologists) 1 and 2.

c) Maternal request for labour analgesia.

d) Age group 18-35 years. 
e) Women in active labour with cervical dilatation in primi about $4-5 \mathrm{~cm}$ and gravida 2 with cervical dilatation of 3 $4 \mathrm{~cm}$.

\section{Exclusion Criteria}

a) Multiple pregnancies or preterm gestation pregnancies.

b) Weight $>90 \mathrm{Kg}$, Age < 18yrs.

c) Allergy to any study drug.

d) Any contraindication to Epidural analgesia like patient refusal, bleeding disorders, localizes infection at the site of injection etc.

Group A:

\section{Technique of CSEA}

CSEA technique can be performed by SINGLE SPACE NEEDLE THROUGH NEEDLE TECHNIQUE.

\section{Patient Position}

- L2-L3 or L3-L4 space identified and skin was infiltrated with small amount of local anesthetic with $25 \mathrm{G}$ needle and skin wheal is created using standard TUHOY needle epidural space is identified .Then a fine bore long spinal needle ( $27 \mathrm{G}$ and $124 \mathrm{~mm}$ or longer) is inserted into sub arachnoid space through the epidural needle. A characteristic pop was felt when spinal needle pierces the duramater and CSF was seen dribbling out.

- A dose containing $1 \mathrm{mg}$ Bupivacaine $+25 \mathrm{mcg}$ Fentanyl making to $1 \mathrm{ml}$ using normal saline was injected into subdural space and needle was withdrawn. - Then the catheter was threaded into the epidural space upto $3-4 \mathrm{~cm}$ length and was taped to back and patient was positioned to supine. Further top ups are given to patient demand through epidural catheter as $10 \mathrm{ml}$ solution containing $0.1 \%$ Bupivacaine + Fentanyl $2 \mathrm{mcg} / \mathrm{ml}$.

GROUP B:

\section{Technique of Epidural Analgesia}

- L2-L3 or L3-L4 space was identified and the skin infiltrated with small amount of local anesthesia with a $25 \mathrm{G}$ needle and skin wheel is created. using standard TUHOY needle epidural space is identified by "Hanging drop" which provides visual identification or "loss of resistance method" which gives evidence of entry into Space regardless of the technique used, it is confirmed that the needle was in Epidural Space. .The epidural space is confirmed by injecting $3 \mathrm{ml}$ of saline or $4-5 \mathrm{cc}$ of air or a test dose of local anesthetic. Patient who did not experience symptoms from test dose received $10 \mathrm{ml}$ Containing $0.1 \%$ Bupivacaine $+2 \mathrm{mcg} / \mathrm{ml}$ of Fentanyl as $3 \mathrm{ml}$ increment in $5 \mathrm{~min}$. - Analgesia was maintained throughout labor by intermittent top ups given, on demand from the patient.

- Pain intensity by using a numeric rating scale.

- $0=$ no pain

- $10=$ worst pain imaginable and sensory levels to pin prick.

- Motor block by using a Bromage scale(0-3 scale)

- side effects like Nausea, Pruritis and Respiratorv depression were assessed at baseline $5 \mathrm{~min}, 15 \mathrm{~min}, 30 \mathrm{~min}, 45 \mathrm{~min}$, $60 \mathrm{~min}$, then every $2 \mathrm{hrs}$ until complete cervical dilatation and at delivery.

- Patients were asked to rate the pain intensity during uterine contractions.

- Patient satisfaction was assessed immediately after delivery as excellent good, fair and poor.

\section{Analysis of Results}

Statistical analysis were performed by

- Data was presented as mean SD.

- P value of less than 0.05 was considered statistically significant. 


\section{JMSCR Vol||07||Issue||03||Page 1016-1026||March}

Observation and Results

Distribution of Age between CSEA and LEA

Table 1 and Figure 1 shows the age distribution in study.

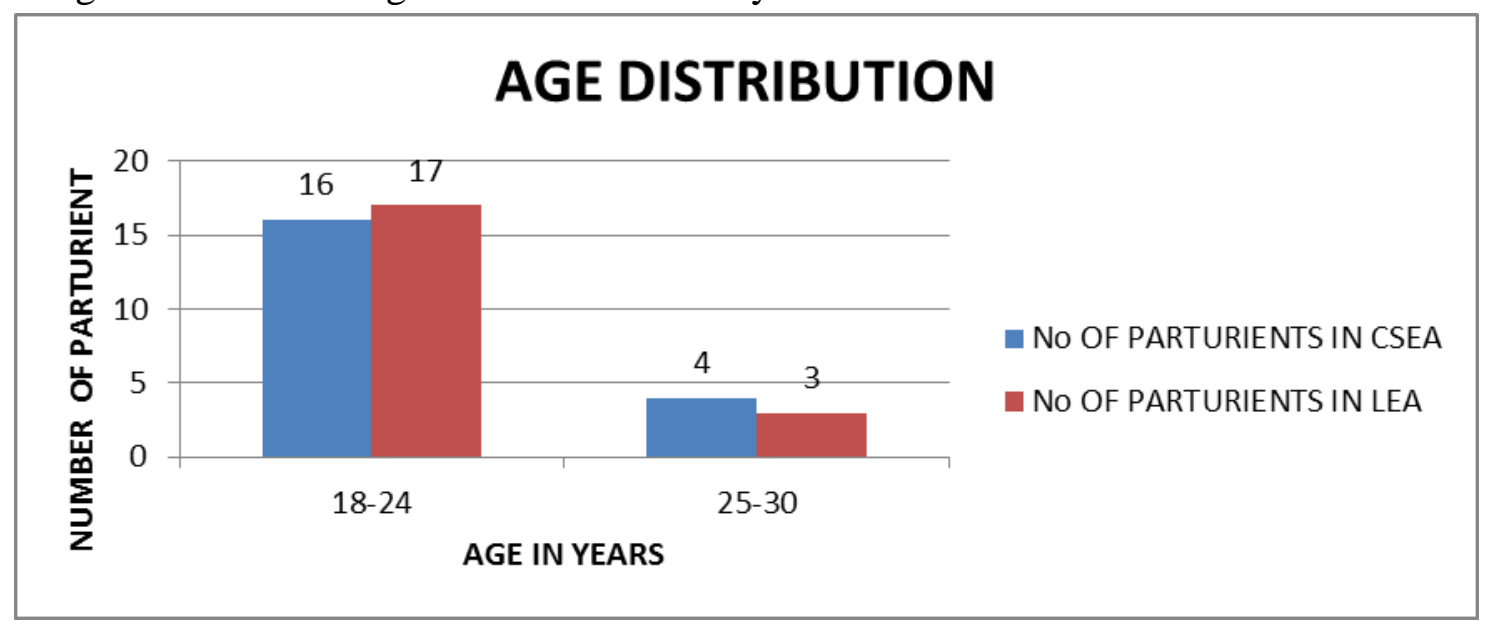

\begin{tabular}{|l|c|c|}
\hline AGE YRS & No OF PARTURIENTS IN CSEA & No OF PARTURIENTS IN LEA \\
\hline $18-24$ & 16 & 17 \\
\hline $25-30$ & 4 & 3 \\
\hline
\end{tabular}

Sixteen parturient in Group A and Seventeen parturient in Group B were within the age goup of 19-25 yrs. Most Of our parturient in the study group are in this range of age group. Four parturients in Group A and three parturients in group 3 were in the age group of 26-30yrs. It was observed that the mean age in group A was
$22.65 \pm 2.45$ and mean age group in Group B was $21.7 \pm 1.94$

Statistical analysis of age distribution was compared between two groups using Standard error of difference between means.The $\mathrm{P}$ value is $>0.05$ so statistically no difference exists between two groups in respect to age distribution.

Table 2 and fig 2.shows height distribution in the study

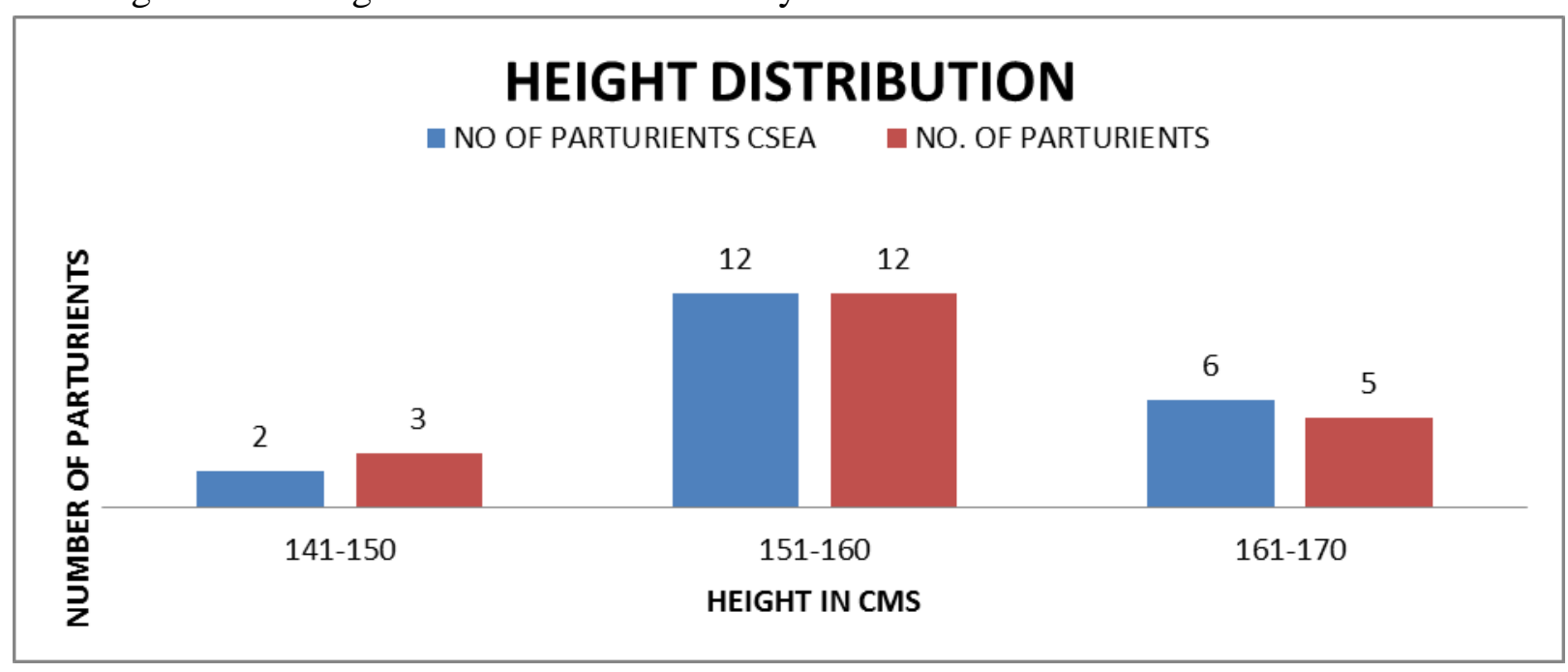

\begin{tabular}{|l|c|c|}
\hline HEIGHT IN CM & NO OF PARTURIENTS CSEA & NO. OF PARTURIENTS \\
\hline $141-150$ & 2 & 3 \\
\hline $151-160$ & 12 & 12 \\
\hline $161-170$ & 6 & 5 \\
\hline
\end{tabular}




\section{JMSCR Vol||07||Issue||03||Page 1016-1026||March}

It was observed that 12 parturients from each group in height range of $151-160 \mathrm{~cm} .6$ parturients from group A and 5 parturients from group B were in the height range of $161-170 \mathrm{~cm}$ and 2 parturients from group A ,3 parturients from group B were in the height range of $141-150 \mathrm{~cm}$ The mean height in group A was 157.25 \pm 4.8 , mean height in group B was $158 \pm 5.9$ with $\mathrm{p}$ value of $>0.05$ was statistically not significant.

Table 3 and figure 3 Shows the weight distribution in the study.

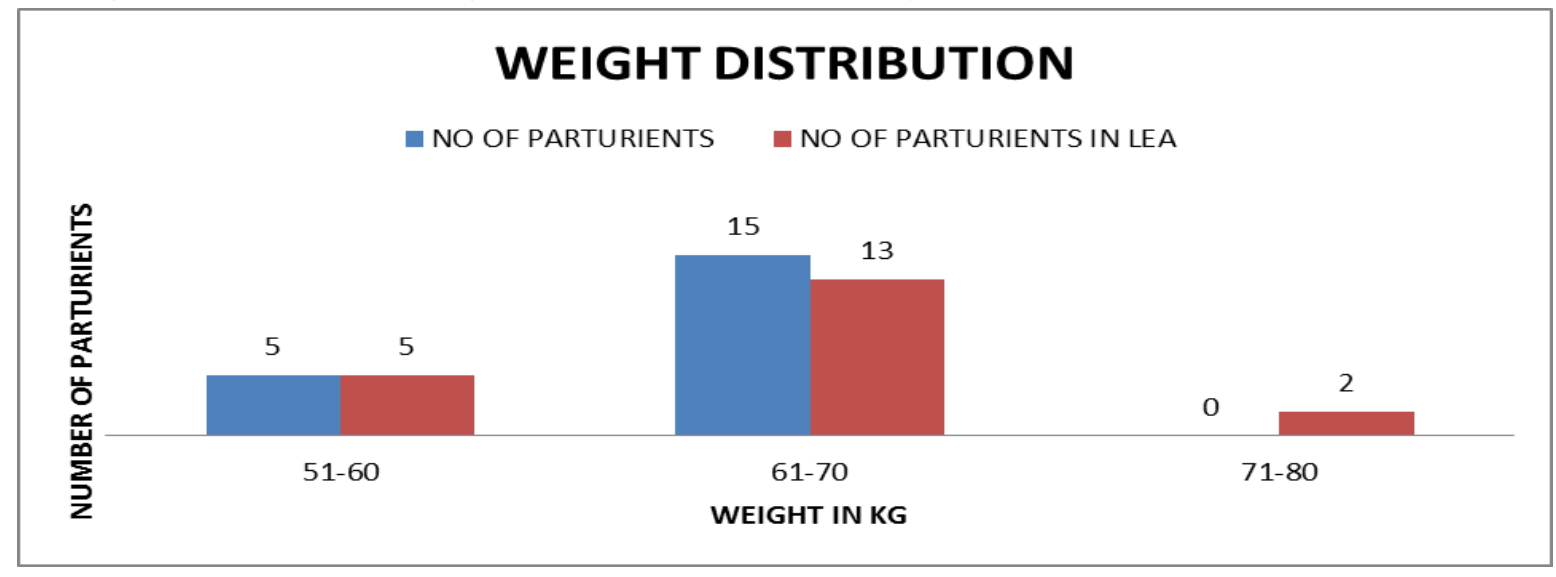

\begin{tabular}{|l|c|c|}
\hline WEIGHT IN KG & NO OF PARTURIENTS & NO OF PARTURIENTS IN LEA \\
\hline $51-60$ & 5 & 5 \\
\hline $61-70$ & 15 & 13 \\
\hline $71-80$ & 0 & 2 \\
\hline
\end{tabular}

Fifteen Parturients from Group A thirteen parturients in Group B were in weight of 61$70 \mathrm{kgs}$, five parturients from each group were in weight range of $51-60 \mathrm{kgs}, 2$ parturients from group B were in weight range of 71 - 80kgs.
It was observed that the mean in Group A was $62.2 \pm 2.25$ and the mean in Group B was 62.15 \pm $5.53)$.

Statistical analysis was done using Standard error of difference between means and is not significant.

\section{Distribution between CSEA and LEA}

Table no 4 and figure 4 shows the number of Nulliparous and parous parturients in each group

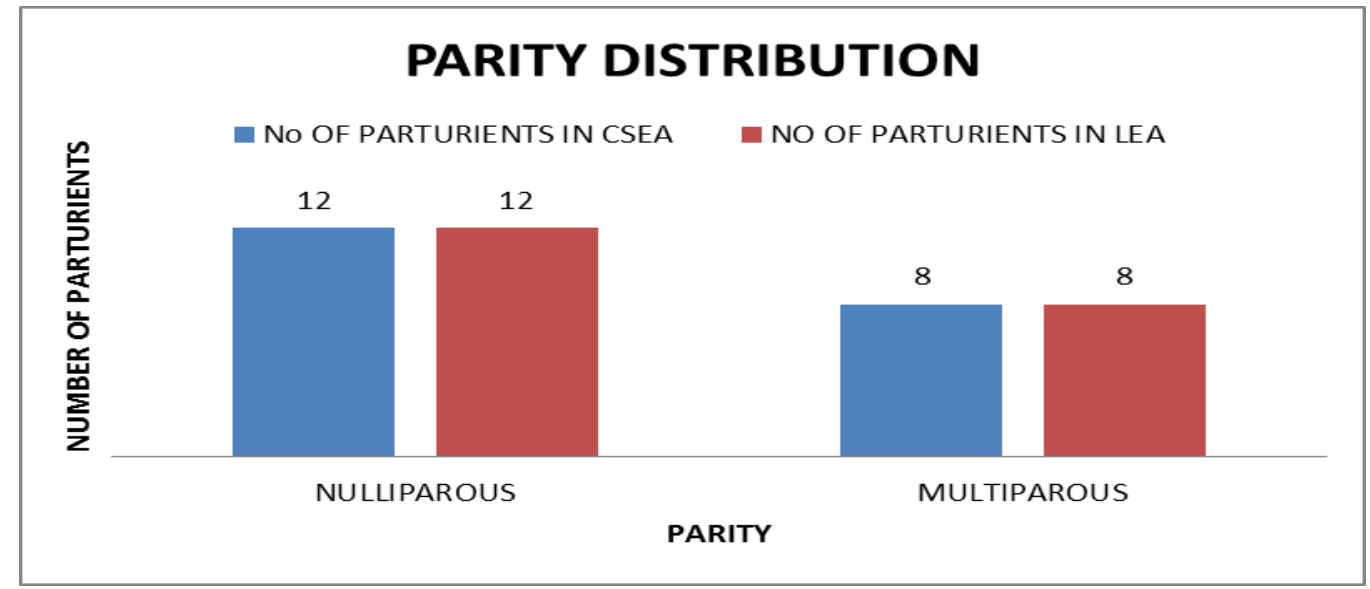

\begin{tabular}{|l|c|c|}
\hline PARITY & No OF PARTURIENTS IN CSEA & NO OF PARTURIENTS IN LEA \\
\hline NULLIPAROUS & 12 & 12 \\
\hline MULTIPAROUS & 8 & 8 \\
\hline
\end{tabular}




\section{JMSCR Vol||07||Issue||03||Page 1016-1026||March}

It was observed that twelve parturients from CSEA group and twelve parturients from LEA group were Nulliparous and eight parturients from each group were Parous.

\section{Onset of Analgesia between CSE and LEA}

Table no 5 and figure 5 shows onset of analgesia after intrathecal administration in Group A and, after administration of bolus Epidural dose in Group B.

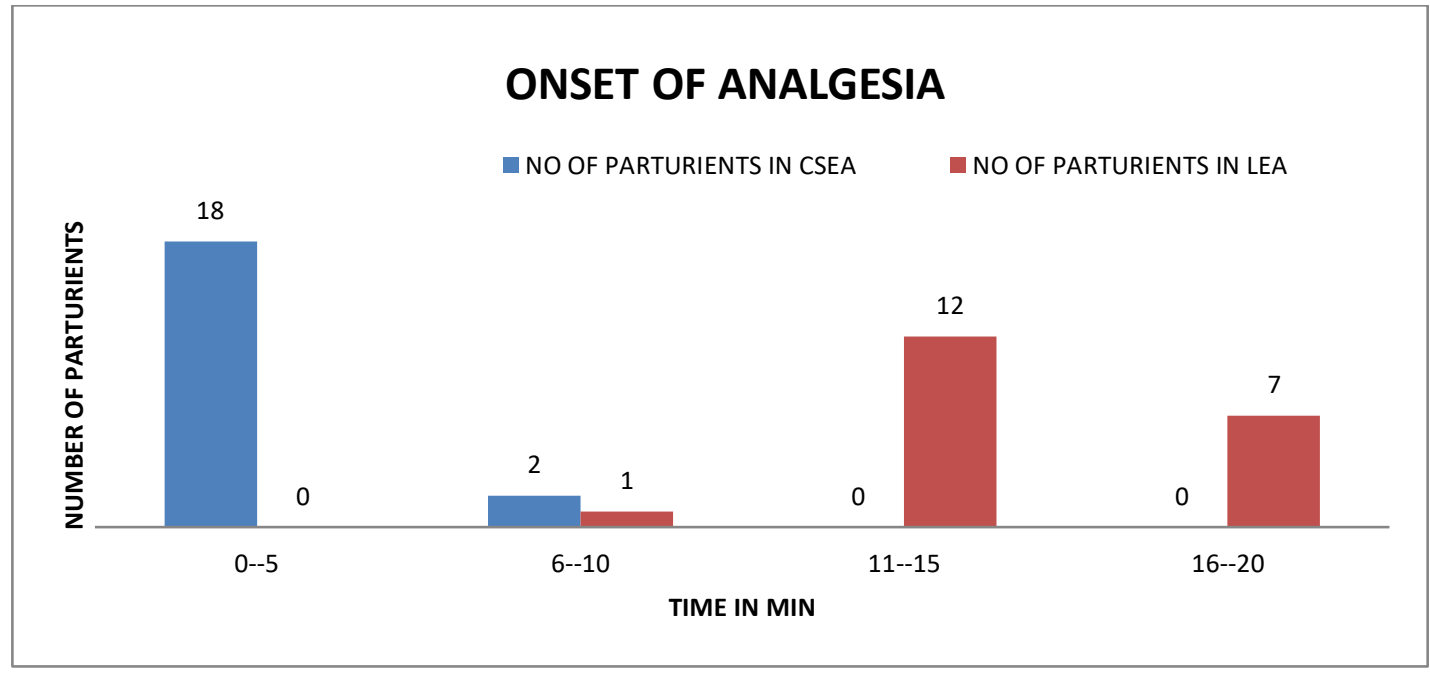

\begin{tabular}{|l|c|c|}
\hline $\begin{array}{l}\text { ONSET OF ANALGESIA } \\
\text { IN MIN }\end{array}$ & $\begin{array}{c}\text { NO OF PARTURIENTS IN } \\
\text { CSEA }\end{array}$ & $\begin{array}{c}\text { NO OF PARTURIENTS IN } \\
\text { LEA }\end{array}$ \\
\hline $0-5$ & 18 & 0 \\
\hline $6-10$ & 2 & 1 \\
\hline $11--15$ & 0 & 12 \\
\hline $16--20$ & 0 & 7 \\
\hline
\end{tabular}

Eighteen parturients from CSEA had onset of analgesia in less than $5 \mathrm{~min}$, twelve parturient from LEA group had Onset of analgesia between 11 to $15 \mathrm{~min}$ and seven parturients had onset of analgesia between 16-20min.

The mean time of onset of analgesia in Group A was $5.05 \pm 2.25 \mathrm{Min}$. The mean time of onset of analgesia in Group B was $15.2 \pm 1.93$ Min. The statistical analysis was done using Standard error of difference between means and $p$ value of $<0.05$ indicating significant difference in onset of analgesia between two techniques.

Duration of Analgesia Distribution between CSEA and LEA

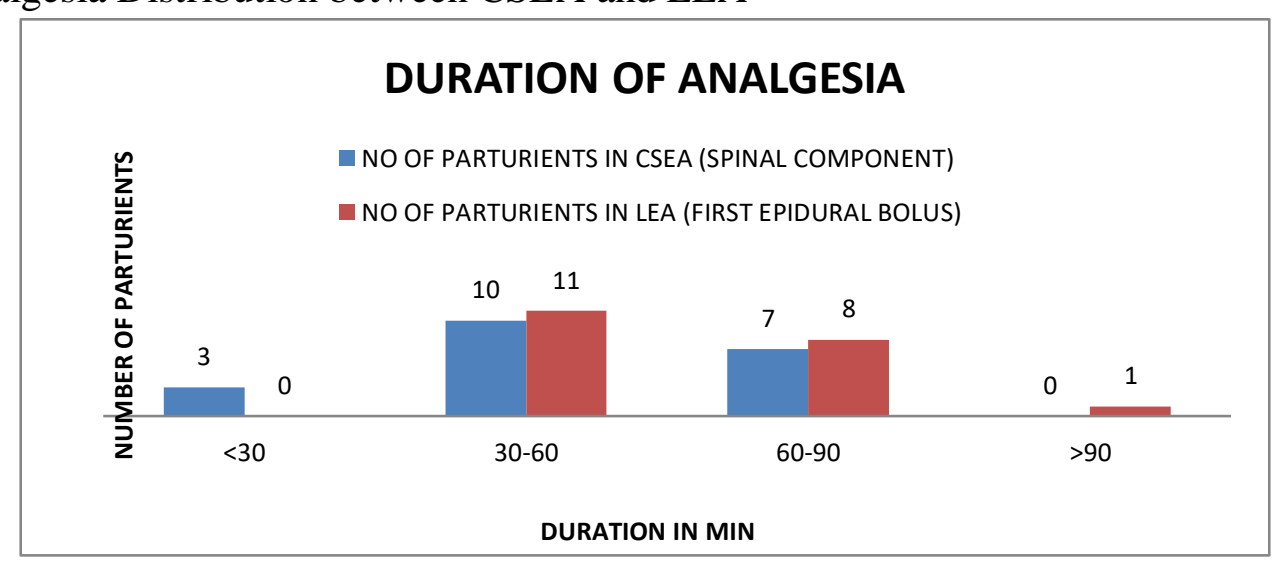




\begin{tabular}{|l|c|c|}
\hline DURATION IN MIN & $\begin{array}{c}\text { NO OF PARTURIENTS IN CSEA } \\
\text { (SPINAL COMPONENT) }\end{array}$ & $\begin{array}{c}\text { NO OF PARTURIENTS IN LEA } \\
\text { (FIRST EPIDURAL BOLUS) }\end{array}$ \\
\hline$<30$ & $\mathbf{3}$ & $\mathbf{0}$ \\
\hline $\mathbf{3 0 - 6 0}$ & $\mathbf{1 0}$ & $\mathbf{1 1}$ \\
\hline $60-90$ & 7 & $\mathbf{8}$ \\
\hline$>90$ & 0 & 1 \\
\hline
\end{tabular}

Three parturients from group A asked for analgesia in $<30 \mathrm{~min} .10$ parturients from group A and 11 parturients from group B were in range of 30 to $60 \mathrm{~min} .7$ parurients from group $\mathrm{A}$ and 8 parturients from group B and 1 parturient from group B had analgesia for $>90 \mathrm{~min}$.
The mean duration for analgesia for spinal dose was $55 \pm 17.70$.

Mean duration for bolus dose of group B $65.75 \pm 12.26$.

$\mathrm{P}$ value of $<0.05$ indicating significant difference between two techniques in duration of analgesia of first dose.

\section{Mode of Delivery distribution between CSEA and LEA}

Table 6 and figure 6 shows mode of delivery in Group A and Group B.

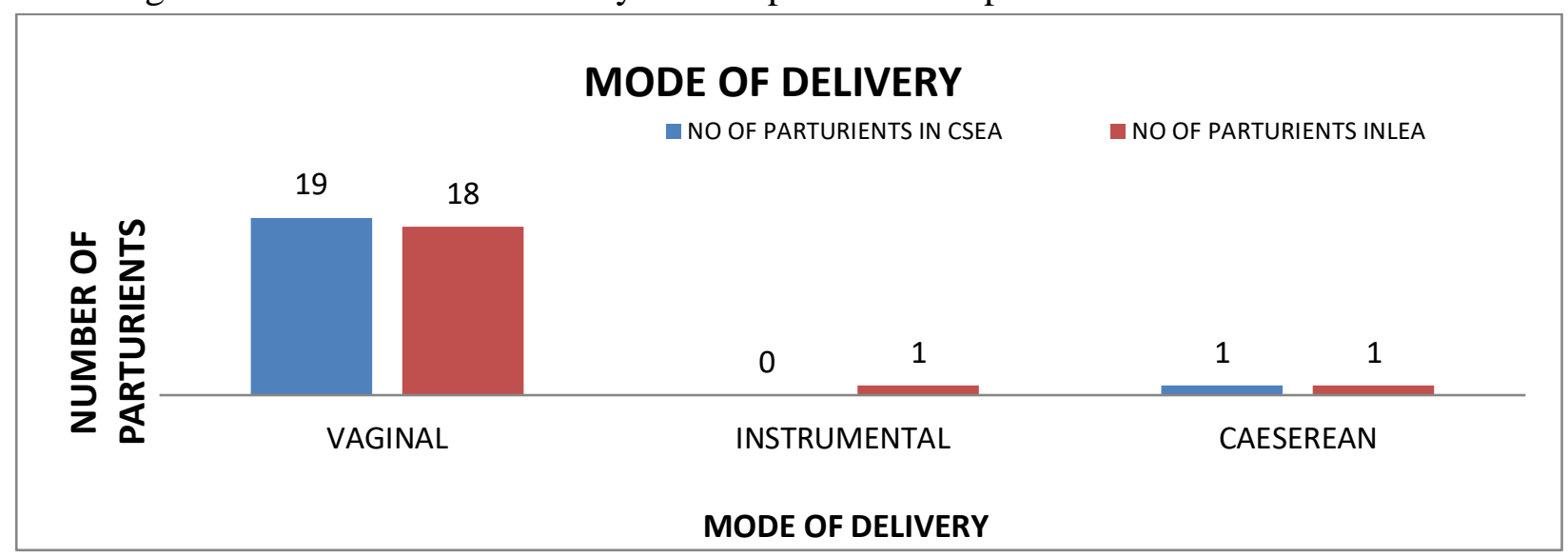

\begin{tabular}{|l|c|c|}
\hline MODE OF DELIVERY & $\begin{array}{c}\text { NO OF PARTURIENTS IN } \\
\text { CSEA }\end{array}$ & $\begin{array}{c}\text { NO OF PARTURIENTS } \\
\text { INLEA }\end{array}$ \\
\hline VAGINAL & 19 & 18 \\
\hline INSTRUMENTAL & 0 & 1 \\
\hline CAESEREAN & 1 & 1 \\
\hline
\end{tabular}

Nineteen parturient from Group A and Eighteen parturients from Group had undergone normal vaginal delivery. One parturient from Group B had underwent caesarian section for different indication. One parturient from Group B had undergone delivery in instrumental mode.
The statistical analysis was done using Chi Square test, The $\mathrm{P}$ value is $>0.05$, so statistically not significant. 


\section{JMSCR Vol||07||Issue||03||Page 1016-1026||March}

Neonatal outcome distribution between CSEA and LEA

Table 7 and figure 7 shows Neonatal outcome in Group A and Group B

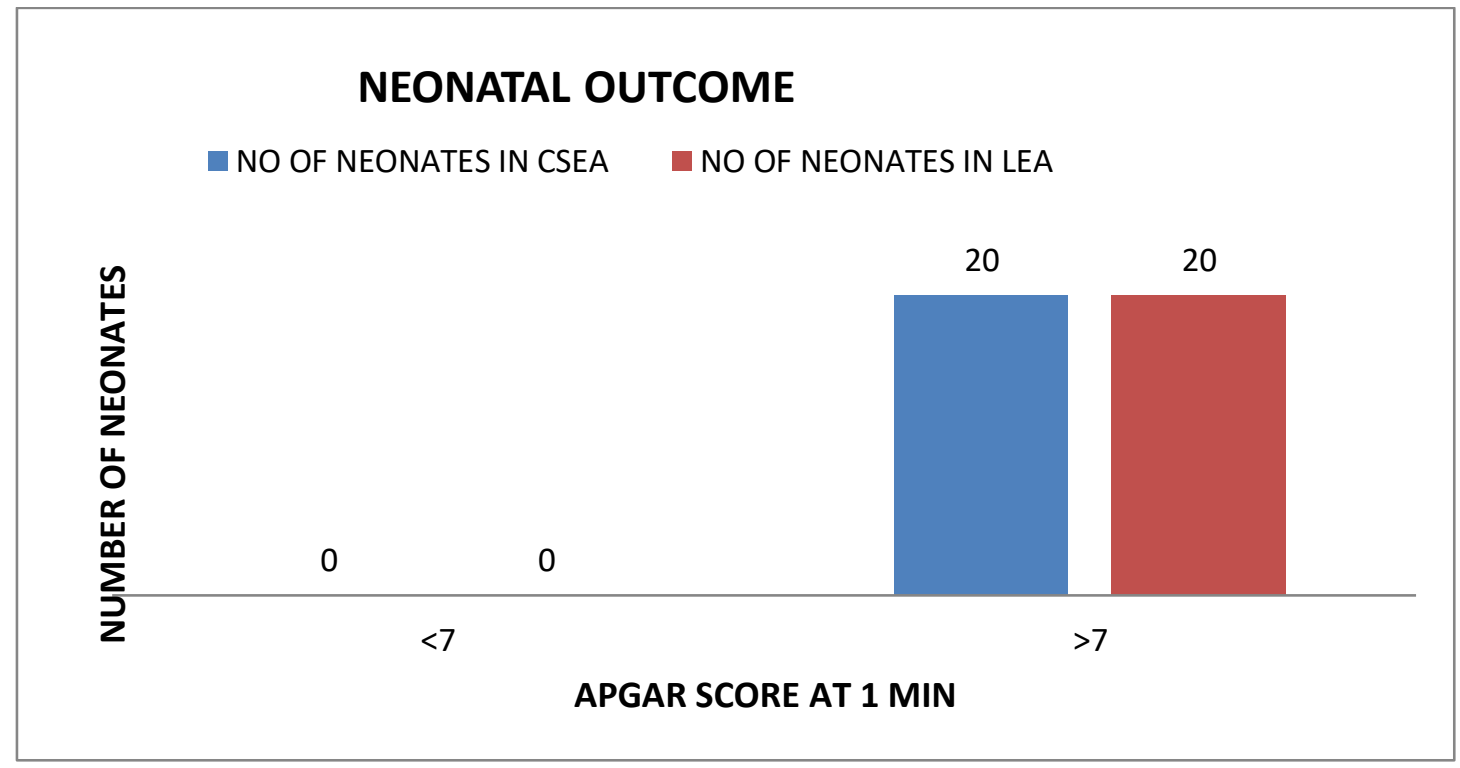

\begin{tabular}{|l|c|c|}
\hline APGAR & NO OF NEONATES IN CSEA & NO OF NEONATES IN LEA \\
\hline$<7$ & 0 & 0 \\
\hline$>7$ & 20 & 20 \\
\hline
\end{tabular}

Neonatal outcome Was graded according to Apgar score of Neonate at 1 st and 5th min after delivery. All the Neonates from Group A and Group B had Apgar score of at 5 th min of delivery .There was no difference in neonatal outcome between two groups.

\section{Complications distribution between CSEA and LEA}

Table 8 and Figure 8 shows the complications that occurred during the period of analgesia in Group A and Group B.

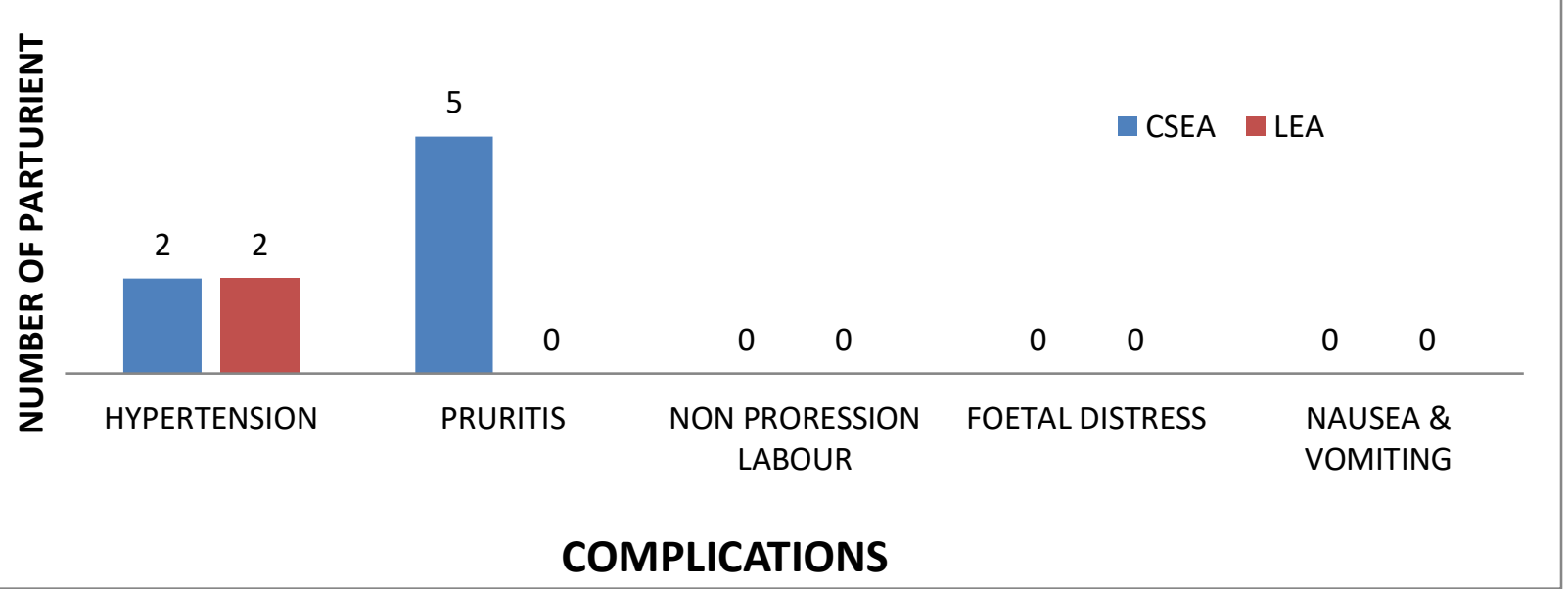

\begin{tabular}{|l|c|c|}
\hline COMPLICATION & CSEA & LEA \\
\hline HYPERTENSION & $\mathbf{2}$ & $\mathbf{2}$ \\
\hline PRURITIS & $\mathbf{5}$ & $\mathbf{0}$ \\
\hline NON PRORESSION LABOUR & $\mathbf{0}$ & $\mathbf{0}$ \\
\hline FOERAL DISTRESS & $\mathbf{0}$ & $\mathbf{0}$ \\
\hline NAUSEA \& VOMITING & $\mathbf{0}$ & $\mathbf{0}$ \\
\hline
\end{tabular}


Five parturients in Group A complained of Pruritis and none of the parturients in group B complained of pruritis. Two parturients from each group had
Hypotension. None of the parturients in neither group had other Complications like nausea and vomiting, non progressive labor or fetal distress.

\section{Maternal Satisfaction Distribution between CSEA and LEA}

Table 9 and fig 9 shows patient satisfaction on analgesia in group A and group B

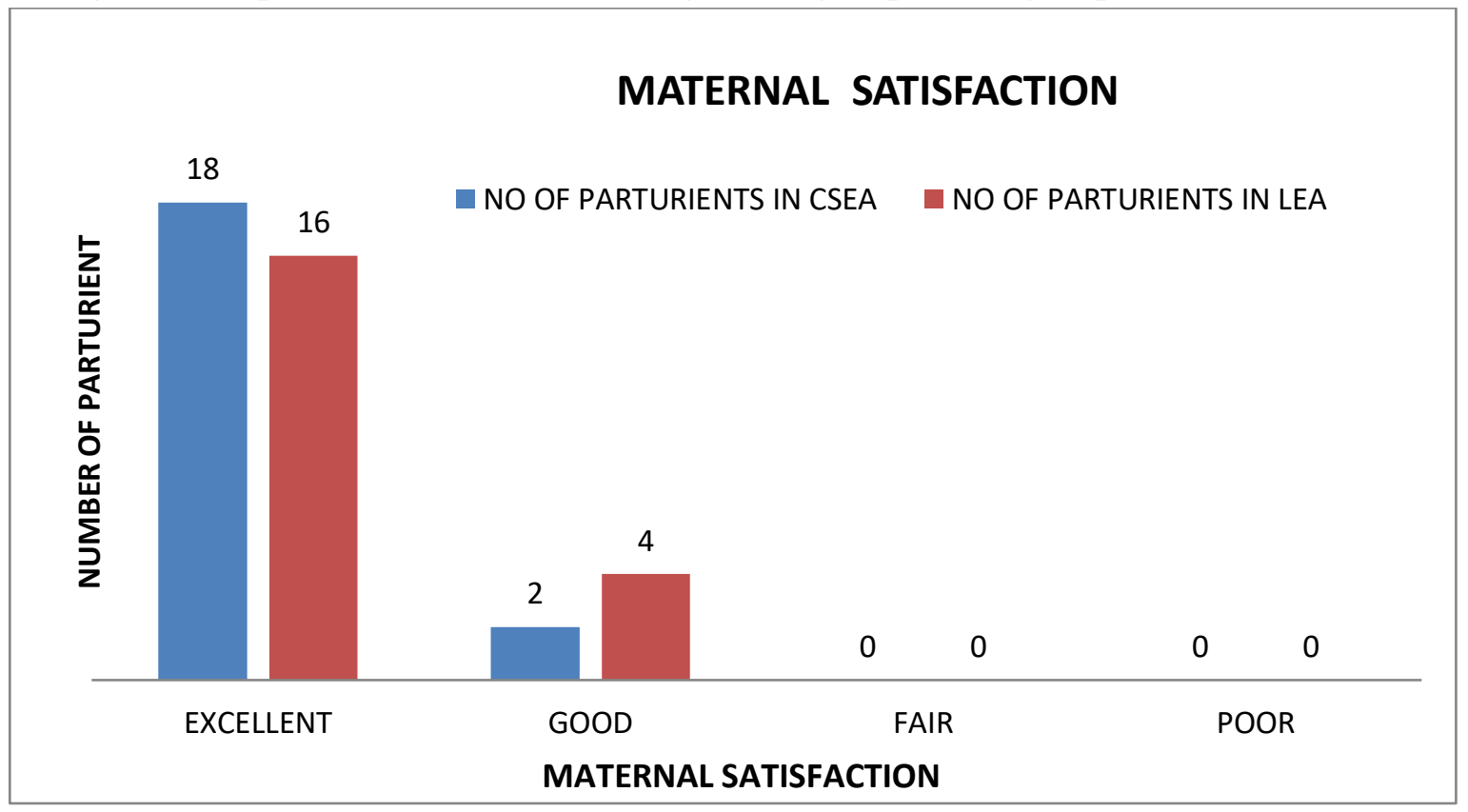

\begin{tabular}{|l|c|c|}
\hline MATERNAL SATISFACTION & $\begin{array}{c}\text { NO OF PARTURIENTS IN } \\
\text { CSEA }\end{array}$ & $\begin{array}{c}\text { NO OF PARTURIENTS IN } \\
\text { LEA }\end{array}$ \\
\hline EXCELLENT & 18 & 16 \\
\hline GOOD & 2 & 4 \\
\hline FAIR & 0 & 0 \\
\hline POOR & 0 & 0 \\
\hline
\end{tabular}

16 parturient from group $\mathrm{A}$ and 18 parturients from group B quoted quality of analgesia as excellent. 4 parturients from group B quoted quality of analgesia as good.

The statistical analysis was done using chi square test.$p$ value is $>0.05$ indicating no significance in maternal satisfaction between two techniques.

\section{Discussion}

Neuraxial analgesia is now considered gold standard for providing pain relief during labour. The CSE technique has gained popularity as it provides rapidity of spinal analgesia, minimal motor blockade and flexibility of epidural catheter to extend the block for caesarean section and for providing post operative analgesia.
Despite advantages regional analgesia may have its own problems, most important of which are its effect on progress of labour and outcome. Epidural analgesia may increase, decrease or have no effect on the rate of cervical dilatation in the first stage of labour .

In the current study fourty parturient of ASA grade 1 or 2 of age group of 19-30 yrs including both primi and parous women were randomly selected and divided into groups A and B.

Group A received Combined spinal epidural technique by needle through needle approach . Group B received Epidural analgesic technique. Except for spinal component both the groups were standardized in respect to drug dosages of epidural component. 
Continuous hemodynamic monitoring was done throughout the process of labour analgesia.

The demographic variables like age, height, weight were similar between two groups.

The statistical analysis of demographic variables is done using the standard error difference between the means. The $p$ value $>0.05$ is statistically not significant.

The onset of analgesia in group A who received combined spinal epidural analgesia is $<5 \mathrm{~min}$ when compared to who received epidural analgesia 1520 min.

On the contrary in the study conducted by Hepner et $\mathrm{al}^{13}$ to compare the CSE and low dose epidural in labour analgesia in respect to initiate and manage motor block onset of analgesia and satisfaction during labour. They observed that there was no difference in either technique motor blockade, parturient satisfaction and the onset of analgesia in epidural group was $<2-5 \mathrm{~min}$.

Duration of analgesia after spinal dose is significantly less than duration of analgesia after onset of analgesia of bolus dose. The mean duration for analgesia for spinal dose in group A was 55+/_17.70.

The mean duration of analgesia of bolus dose in Group B was 65.75+/_12.26.

Three parturient (15\%) from group A complained of pain in $<30 \mathrm{~min}$ where as none of the parturient requested for additional analgesia in Group B within 30min after the onset of analgesia.

In the study conducted by Dr. Sunanda Gupta et al. the effectiveness of CSE was compared with epidural using spinal dose of $1.25 \mathrm{mg}$ bupivacaine plus $25 \mathrm{mcg}$ of fentanyl and bolus epidural dose of $10 \mathrm{ml}$ solution of bupivacaine $+25 \mathrm{mcg}$ of fentanyl. They observed that the interval from initial bolus dose to maternal request for additional analgesia was increased in epidural group compared to CSE group

The mode of delivery between two Groups was similar 19 parturient from group A and the 18 parturient from Group B delivered vaginally one from each Group undergone caesarean section and one parturient from Group B needed instrumental assistance for delivery.

The Neonatal outcome, as assessed by Apgar scores was compared between two groups. Only one neonate had Apgar score of $<7$ at 1 st min from Group A remaining all neonates from both groups had Apgar score $>7$ at 1st and 5th min.

The incidence of side effects between two groups was observed two groups was observed ffive parturient from Group A complaint about Pruritis and none from Group B complained of Pruritis.

Two parturient from either group had Hypotension treated Inj phenylephrine and I.V fluids. Pruritis had been mentioned as main side effect in combined spinal epidural analgesia and study supports incidence of Pruritis in Spinal Epidural group . $25 \%$ of parturient in combined spinal epidural group about pruritis and none from epidural group complained about pruritis. to assess the relative effects of CSE and epidural during labor.

The parturient response to both the technique is Excellent to Good in $100 \%$ of Parturients. The maintenance of maternal expulsive power during second stage of labor, to ability ambulate at their will shows their increased acceptance by the parturient.

\section{Summary}

The present study was done to compare efficacy and safety of two techniques of labor analgesia using COMBINED SPINAL EPIDURAL and EPIDURAL ANALGESIA.

The onset of analgesia, duration of analgesia of first dose (spinal or epidural bolus dose), mode Of delivery, neonatal outcome, maternal and fetal side effects and maternal satisfaction were observed , compared and analyzed statistically.

Continuous hemodynamic monitoring of the mother and fetal heart rate were monitored throughout the process of tabor. There was no statistical significance IpsO.0S) regarding demographic variables, Age, Height, Weight in between two group. Likewise parity status also similar between two groups. 
The onset of analgesia was faster (5min) in combined spinal epidural technique compare with Epidural technique (15-20min). This difference in onset of analgesia was statistically Significant ( $\mathrm{p}$ value $<0.05$. Mode of delivery was similar and neonatal outcome was good and equal in both groups without any statistical significant difference.

The incidence of Pruritis was more in combined spinal epidural group than Epidural group. Two parturient from each group had maternal hypotension. None of the parturient from either group had other side effects like nausea, vomiting, urinary retention and respiratory depression.

Overall maternal satisfaction was also similar between two groups.

\section{Conclusion}

From the present study we conclude that both the techniques Combined spinal Epidural and Epidural for labor analgesia produce excellent analgesia. however the CSE technique had faster onset of analgesia when compared to Epidural technique. Both the technique were similar in terms of safety and efficacy.

The present study would have been more effective if the study had done on larger sample of parturient's than present study and also could be done by reducing the concentration of Bupivacaine to $0.0625 \%$

\section{References}

1. Maltau JM, Eielsen OV, Stokke KT. Effect of stress during labor on the concentration of cortisol and estriol in maternal plasma. Am J ObstetGynecol 1979;134:681

2. Holdcroft A. Regional Anaesthetic Techniques. In: Principles and Practice of Obstetric Anaesthesia and Analgesia. Ch. 15. Philadelphia, PA: Black Well Science Publishers; 2000. p. 243-59.

3. Falconer AD, Powles AB. Plasma noradrenaline levels during labourinfluence of elective lumbar epidural blockade. Anaesthesiology 1982;37:16-8.
4. Sanguol F, Fox GS, Houle GL. Effects of regional analgesia on maternal oxygen consumption during the first stage of labour. Am J ObstetGynecol 1975;121:1086-9

5. Marx GF, Greene NM, Maternal lactate, pyruvate and excess pyruvate production during labour and delivery. Am J ObstetGynecol 1964;90:786-9

6. Livinson G, Shnider SM, De Loremen AA, Steffenson JL. Effects of maternal hyperventilation on uterine blood flow and foetal oxygenation and acid base status. Anaesthesiology 1974;40:340-7.

7. T Chia, Y \& Arulkumaran, Sabaratnam \& Chua, Soo \& S Ratnam, S. (1990). Effectiveness of Transcutaneous Electric Nerve Stimulator for Pain Relief in Labour. Asia-Oceania journal of obstetrics and gynaecology / AOFOG. 16. 145-51. 10.1111/j.1447-0756.1990.tb00017.x.

8. Hawkins JL. Epidural analgesia for Labour and delivery. N Engl J Med 2010;362: 1503-10.

9. Jung H, Kwak KH. Neuraxial analgesia: a review of its effects on the outcome and duration of labor. Korean $\mathrm{J}$ Anesthesiol. 2013;65(5):379-84.

10. Hitzeman N, Chin S. Epidural analgesia for labor pain. Am Fam Physician. 2012;86(3):241-2.

11. Anim-Somuah M, Smyth RM, Jones L. Epidural versus non-epidural or no analgesia in labour. Cochrane Database Syst Rev. 2011(12):Cd000331.

12. Norris MC, Fogel ST, Conway-Long C. Combined spinal-epidural versus epidural labor analgesia. Anesthesiology. 2001;95:913-20.

13. Hepner DL, Gaiser RR,Cheek TG and Gutsche BB. Comparision of combined spinal epidural and low dose epidural for labour analgesia .Can Anesth,2000 47:3;232-6. 